\title{
Syarat Perlu dan Cukup untuk Keterbatasan Potensial Riesz di Ruang Morrey Klasik
}

\author{
Mohammad Imam Utoyo $^{\left.1^{*}\right)}$, Basuki Widodo ${ }^{2)}$, Toto Nusantara ${ }^{3)}$, dan Suhariningsih ${ }^{4)}$ \\ ${ }^{1)}$ Departemen Matematika, FST Universitas Airlangga, Surabaya 60115 \\ 2) Jurusan Matematika, Fakultas Matematika dan Ilmu Pengetahuan Alam, Institut Teknologi Surabaya, Surabaya 60111 \\ ${ }^{3)}$ Departemen Fisika, FST Universitas Airlangga, Surabaya 60115 \\ ${ }^{4)}$ Departemen Matematika, Universitas Negeri Malang, Malang 65145
}

Diterima 11-05-2011 Disetujui 21-06-2012

\begin{abstract}
This script was aimed to determine the necessary conditions for boundedness of Riesz potential in the classical Morrey space. If these results are combined with previous research results will be obtained the necessary and sufficient condition for boundedness of Riesz potential. This necessary condition is obtained through the use of characteristic function as one member of the classical Morrey space.
\end{abstract}

Keywords: boundedness, classical Morrey space, Riesz potential

\begin{abstract}
ABSTRAK
Tujuan tulisan ini adalah menentukan syarat perlu untuk keterbatasan potential Riesz pada ruang Morrey klasik. Jika hasil ini dikombinasikan dengan hasil-hasil penelitian sebelumnya akan diperoleh syarat perlu dan cukup untuk keterbatasan potential Riesz pada ruang Morrey klasik. Syarat perlu ini diperoleh melalui pemakaian fungsi karakteristik sebagai salah satu anggota dari ruang Morrey klasik.
\end{abstract}

Kata kunci: keterbatasan, potensial Riesz, ruang Morrey klasik

\section{PENDAHULUAN}

Operator $T$ dikatakan terbatas dari ruang $X$ ke ruang $Y$, jika terdapat $C>1$ sehingga $\|T x: Y\| \leq C\|x\|$ dengan $\|x: X\|$ menotasikan norma $x$ di ruang $X$. Selanjutnya operator $T$ dikatakan terbatas di ruang $X$, jika $T$ terbatas dari ruang $X$ ke ruang $X$.

Potensial Riesz didefinisikan oleh

$$
I_{\alpha} f(x)=\int_{R^{n}} \frac{f(y)}{|x-y|^{n-\alpha}} d y,
$$

dengan $x \in R^{n}$ dan $0<\alpha<n$.

Keterbatasan potensial Riesz telah banyak diteliti di berbagai ruang, diantaranya di ruang Lebesgue (Duoandikoetxea 2001), di ruang Morrey klasik (Peetre 1969), dan ruang Morrey (Nakai 1994).

\footnotetext{
*Telp: +6281615211250

Email: m_oetojo@yahoo.com
}

Ruang Lebesgue $L^{p}=L^{p}\left(R^{n}\right), \quad 1 \leq p<\infty$, didefinisikan sebagai ruang kelas-kelas ekivalen $f$ sehingga

$$
\left\|f: L^{p}\right\|=\left(\int_{R^{n}}|f(y)|^{p} d y\right)^{1 / p}<\infty
$$

Oleh karena setiap anggota dari ruang Morrey klasik merupakan anggota ruang Lebesgue lokal, maka sebelum mendefinisikan ruang Morrey klasik terlebih dahulu didefinisikan ruang Lebesgue lokal.

Ruang Lebesgue lokal, $L_{l o k}^{p}=L_{l o k}^{p}\left(R^{n}\right), 1 \leq p<\infty$, didefinisikan sebagai ruang kelas-kelas ekivalen $f$ sehingga untuk setiap subhimpunan kompak $S$ di $R^{n}$ berlaku $\int_{S}|f(y)|^{p} d y<\infty$. Selanjutnya ruang Morrey klasik didefinisikan sebagai berikut:

Misalkan $B(a, r)$ adalah bola berpusat di $a \in R^{n}$ dan berjarijari $r>0,1 \leq p<\infty$ dan $0 \leq \lambda<n$. Ruang Morrey klasik, 
$L^{p, \lambda}=L^{p, \lambda}\left(R^{n}\right)$, didefinisikan sebagai himpunan semua $f \in L_{\text {lok }}^{p}$ sehingga

$$
\left\|f: L^{p, \lambda}\right\|=\sup _{B=B(a, r)}\left(\frac{1}{r^{\lambda}} \int_{R^{n}}|f(y)|^{p} d y\right)^{1 / p}<\infty .
$$

Ruang Lebesgue merupakan bentuk khusus dari ruang Morrey klasik sebab jika $\lambda=0$, maka $L^{p, \lambda}=L^{p}$.

Hasil penelitian terdahulu tentang keterbatasan potensial Riesz yang didefinisikan pada $R^{n}$ di ruang Morrey klasik diberikan dalam teorema berikut ini.

Teorema A. (Adams-Chiarenza-Frasca) Misalkan $0<\lambda<n-\alpha p$ dan $1<p<\frac{n}{\alpha}$. Jika $\frac{1}{q}=\frac{1}{p}-\frac{\alpha}{n-\lambda}$, maka terdapat konstanta $C_{p, q}>0$ sehingga untuk semua $f \in L^{p, \lambda}$ berlaku

$\left\|I_{\alpha} f: L^{q, \lambda}\right\| \leq C_{p, q}\left\|f: L^{p, \lambda}\right\|($ Chiarenza \& Frasca 1987)

Teorema B. (Spanne) Misalkan $0<\lambda, \mu<n$, $1<p<\frac{n}{\alpha}$, dan $\lambda q=\mu p$. Jika $\frac{1}{q}=\frac{1}{p}-\frac{\alpha}{n}$, maka terdapat $C_{p, q}>0$ sehingga untuk semua $f \in L^{p, \lambda}$ berlaku

$$
\left\|I_{\alpha} f: L^{q, \mu}\right\| \leq C_{p, q}\left\|f: L^{p, \lambda}\right\|
$$

(Peetre 1969)

Kedua teorema di atas berbentuk implikasi. Hal ini mengisyaratkan bahwa kedua teorema tersebut tidak memuat syarat perlu untuk keterbatasan potensial Riesz. Di samping teorema berbentuk implikasi di atas terdapat teorema keterbatasan potensial Riesz lainnya yang berbentuk biimplikasi, yaitu teorema keterbatasan potensial Riesz di ruang Lebesgue yang diberikan diberikan dalam teorema berikut ini (Krantz 1999).

Teorema C. Misalkan $1<p<\frac{n}{\alpha}$. Operator $I_{\alpha}$ terbatas dari $L^{p}$ ke $L^{q}$ jika dan hanya jika $\frac{1}{q}=\frac{1}{p}-\frac{\alpha}{n}$.

Teorema hasil penelitian lainnya yang berbentuk biimplikasi diantaranya adalah teorema keterbatasan operator integral fraksional yang didefinisikan pada ruang kuasi metrik (Eridani et al. 2009) dan dalam Edmunds et al. (2002). Pembuktian syarat perlu dari keterbatasan $I_{\alpha}$ di ruang Lebesgue dilakukan dengan menggunakan operator dilatasi sedangkan pada ruang kuasi metrik menggunakan fungsi karakteristik. Dimotivasi oleh teorema-teorema berbentuk biimplikasi di atas, penulis tertarik untuk menemukan syarat perlu untuk keterbatasan $I_{\alpha}$ di Ruang Morrey klasik dan membuktikan hasilnya dengan menggunakan fungsi karakteristik.

\section{HASIL DAN PEMBAHASAN}

Prosisi berikut ini menyatakan bahwa $L^{p, \lambda}$ merupakan himpunan tak kosong. Di samping itu proposisi ini juga diperlukan dalam menentukan syarat perlu keterbatasan potensial Riesz di ruang $L^{p, \lambda}$.

Proposisi 1. Untuk setiap bola $B_{o}:=B\left(a_{o}, r_{o}\right)$ dalam $R^{n}$ terdapat $C>0$ sehingga:

a. $r_{o}^{\alpha} \leq C I_{\alpha} \chi_{B_{o}}$ dengan $\chi_{B_{o}}$ merupakan fungsi karakteristik

b. $\left\|\chi_{B_{o}}: L^{p, \lambda}\right\| \leq C r_{o}^{\frac{n-\lambda}{p}}$

Bukti: Diambil sebarang bola $B_{o}:=B\left(a_{o}, r_{o}\right)$ dalam $R^{n}$.

a. Diambil sebarang $(x, y) \in B_{o}$, maka $|x-y| \leq\left|x-a_{o}\right|+\left|a_{o}-y\right|<2 r_{o}$, sehingga $\frac{1}{r_{o}^{n-\alpha}} \leq \frac{C}{|x-y|^{n-\alpha}}$.

Oleh karena itu $r_{o}^{\alpha} \leq \int_{B_{o}} \frac{C}{|x-y|^{n-\alpha}} d y=C \int_{R^{n}} \frac{\chi_{B_{o}}(y)}{|x-y|^{n-\alpha}} d y=C I_{\alpha} \chi_{B_{o}}(y)$.

b. Diambil sebarang bola $B$ dalam $R^{n}$, misalkan $B:=B(a, r)$.

Karena $\frac{1}{r^{\lambda}} \int_{B}\left|\chi_{B_{o}}\right| d y=\frac{1}{r^{\lambda}} \int_{B \cap B_{o}} d y \leq C r_{o}^{n-\lambda}$,

maka $\left\|\chi_{B_{o}}: L^{p, \lambda}\right\| \leq C r_{o}^{\frac{n-\lambda}{p}}$.

Berdasarkan Proposisi 1 di atas diperoleh bahwa untuk setiap bola $B_{o}:=B\left(a_{o}, r_{o}\right)$ dalam $R^{n}, \chi_{B_{o}} \in L^{p, \lambda}$.

Teorema berikut ini memuat syarat perlu dan cukup untuk keterbatasan potensial Riesz di ruang Morrey klasik.

Teorema 1. Misalkan $0<\lambda<n-\alpha p$ dan $1<p<\frac{n}{\alpha}$. Syarat perlu dan cukup untuk keterbatasan $I_{\alpha}$ dari ruang $L^{p, \lambda}$ ke ruang $L^{q, \lambda}$ adalah $\frac{1}{q}=\frac{1}{p}-\frac{\alpha}{n-\lambda}$.

Bukti: Syarat cukup. Bukti syarat cukup untuk keterbatasan $I_{\alpha}$ dari ruang $L^{p, \lambda}$ ke ruang $L^{q, \lambda}$ dapat dilihat di (Chiarenza \& Fraca 1987).

Syarat perlu. Misalkan $I_{\alpha}$ terbatas dari ruang $L^{p, \lambda}$ ke ruang $L^{q, \lambda}$. Diambil sebarang bola $B_{o}:=B\left(a_{o}, r_{o}\right)$ dalam $R^{n}$. Berdasarkan proposisi 1b diperoleh $\chi_{B_{o}} \in L^{p, \lambda}$. Oleh karena itu terdapat konstanta $C>1$ sehingga

$$
\left\|I_{\alpha} \chi_{B_{o}}: L^{q, \lambda}\right\| \leq C\left\|\chi_{B_{o}}: L^{p, \lambda}\right\|
$$

Berdasarkan proposisi 1a, (1), dan definisi ruang Morrey klasik diperoleh 


$$
\begin{gathered}
\left(\frac{1}{r_{o}^{\lambda}} \int_{B_{o}} r_{o}^{\alpha q} d y\right)^{\frac{1}{q}} \leq C r_{o}^{\frac{n-\lambda}{p}} \\
r_{o}^{\alpha q+n-\lambda-\frac{(n-\lambda) q}{p}} \leq C .
\end{gathered}
$$

Karena pertidaksamaan terakhir herlaku untuk sebarang bola $B_{o}$, maka $\alpha q+n-\lambda-\frac{(n-\lambda) q}{p}=0$.

$$
\text { sehingga } \quad \frac{1}{q}=\frac{1}{p}-\frac{\alpha}{n-\lambda} \text {. }
$$

Teorema 2. Misalkan $0<\lambda, \mu<n$, dan $1<p<\frac{n}{\alpha}$, dan $\lambda q=\mu p$. Syarat perlu dan cukup untuk keterbatasan $I_{\alpha}$ dari ruang $L^{p, \lambda}$ ke ruang $L^{q, \mu}$ adalah $\frac{1}{q}=\frac{1}{p}-\frac{\alpha}{n}$.

Bukti: Syarat cukup. Bukti syarat cukup untuk keterbatasan $I_{\alpha}$ dari ruang $L^{p, \lambda}$ ke ruang $L^{q, \mu}$ dapat dilihat di Peetre (1969).

Syarat perlu. Misalkan $I_{\alpha}$ terbatas dari ruang $L^{p, \lambda}$ ke ruang $L^{q, \mu}$. Diambil sebarang bola $B_{o}:=B\left(a_{o}, r_{o}\right)$ dalam $R^{n}$. Berdasarkan proposisi $1 \mathrm{~b}$ diperoleh $\chi_{B_{o}} \in L^{p, \lambda}$. Oleh karena itu terdapat konstanta $C>1$ sehingga

$$
\left\|I_{\alpha} \chi_{B_{O}}: L^{q, \mu}\right\| \leq C\left\|\chi_{B_{o}}: L^{p, \lambda}\right\|
$$

Berdasarkan proposisi 1a, (2), dan definisi ruang Morrey klasik diperoleh $\left(\frac{1}{r_{o}^{\mu}} \int_{B_{O}} r_{o}^{\alpha q} d y\right)^{\frac{1}{q}} \leq C r_{o}^{\frac{n-\lambda}{p}}$

$$
r_{o}^{\alpha q+n-\mu-\frac{(n-\lambda) q}{p}} \leq C .
$$

Karena pertidaksamaan terakhir berlaku untuk sebarang bola $B_{o}$, maka $\alpha q+n-\mu-\frac{(n-\lambda) q}{p}=0$. sehingga $\frac{1}{q}=\frac{1}{p}-\frac{\alpha}{n}$.

\section{SIMPULAN}

Syarat perlu untuk keterbatasan potensial Riesz di ruang Morrey klasik dapat dicari melalui penggunaan fungsi karakteristik. Fungsi karakteristik ini diduga dapat digunakan untuk menentukan syarat perlu untuk keterbatasan potensial Riesz dan operator integral lainnya di ruang lainnya pula.

Oleh karena itu tindak lanjut penelitian ini adalah mencari syarat perlu untuk keterbatasan potensial Riesz dan operator integral lainnya di ruang lainnya pula.

\section{UCAPAN TERIMAKASIH}

Penulis mengucapkan terimakasih kepada Dr. Eridani dari Departemen Matematika FST UNAIR atas saran dan masukannya selama penelitian ini dilakukan.

\section{DAFTAR PUSTAKA}

Chiarenza, F \& Fraca, M. 1987, Morrey spaces and hardylittlewood maximal functions. Rend Mat 7: 273-279.

Duoandikoetxea, J. 2001. Fourier Analysis, Graduate Studies in Mathematics, Vol. 29. Providence, Rhode Island: American Mathematical Society.

Edmunds, D., Kokilashvili, V \& Meskhi, A. 2002. Bounded and compactIntegral operator, mathematics and its applications, 543, kluwer academics publisher, dordrecht. The Netherlands 24: 367-371, 377-379.

Eridani, Kokilashvill, V \& Meskhi, A. 2009, Morrey space and fractional integral operators. Expo Math 27(3): 227239.

Krantz \& Steven G. 1999. A Panorama of Harmonic Analysis. Washington: The Mathematical Association of America.

Nakai, E. 1994. Hardy-littlewood maximal operator, singular integral operators and the riesz potensials on generalized morrey space. Math Nacr 166: 95-103.

Peetre, J. 1969. On the theory of spaces. J Funct Anal 4: 71-87. 